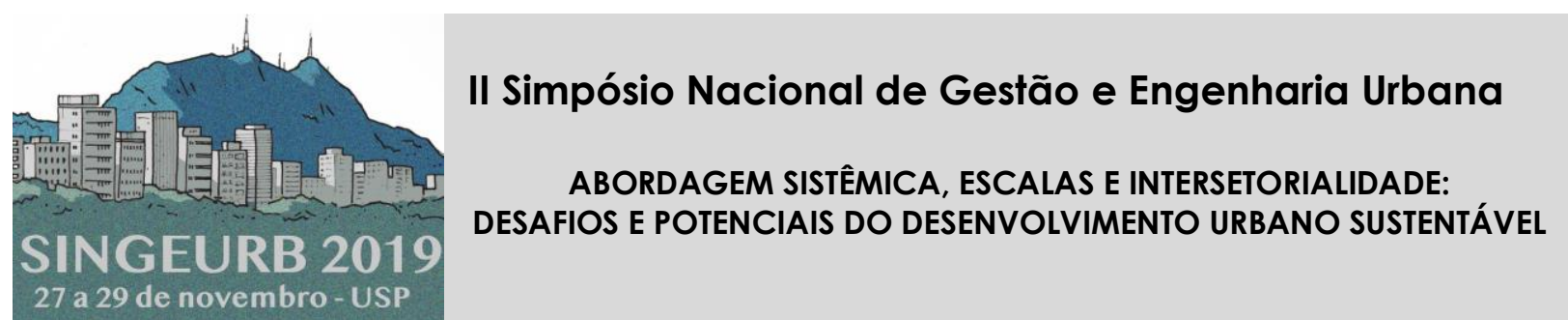

\title{
A importância da participação popular para o estudo da caminhabilidade 1
}

\section{The importance of popular participation in the study of walkability}

\author{
Carvalho, Bady Nunes de"; Barbosa, Gisele S.2 \\ ' Universidade Federal do Rio de Janeiro, Escola Politécnica, Engenharia Civil, \\ Av. Athos da Silveira Ramos, 149, CT, bloco D, sala D101, CEP 21941-909, Brasil, \\ bady.nunes@poli.ufrj.br \\ 2 Universidade Federal do Rio de Janeiro, Escola Politécnica, Departamento \\ de Expressão Gráfica, Programa de Engenharia Urbana
}

\begin{abstract}
RESUMO
Inúmeras vezes os pedestres enfrentam dificuldades de mobilidade nos centros urbanos devido ao intenso tráfego motorizado e a falta de planejamento ou planejamentos que priorizam o automóvel. Nas últimas décadas, estudos sobre mobilidade urbana adquiriram maior importância com objetivo de assegurar o desenvolvimento de cidades com planejamentos voltadas para melhoria do deslocamento do pedestre. Como forma de avaliar essa maior qualidade, são aplicados índices de caminhabilidade, que contemplam uma série de indicadores sobre as condições dos mesmos. O resultado da mensuração desses indicadores consiste na fundamentação de soluções. Nesse contexto, sua efetividade exige o atendimento de uma variável essencial: a participação dos pedestres no processo de construção das alternativas. Com base nessa prerrogativa, este artigo tem como objetivo identificar os elementos inerentes ao conceito de caminhabilidade que tem relação direta com a participação popular. Para tanto, o trabalho adotou como metodologia a revisão bibliográfica relativa a estudos sobre participação popular no planejamento de centros urbanos, conceito de caminhabilidade e modelos de cálculo de indicadores de caminhabilidade. Com base nesse referencial teórico, os modelos revisados são analisados e o estudo, então, destaca a importância da participação popular, sendo base para futuras aplicações nas cidades e para estudos de mobilidade e acessibilidade.
\end{abstract}

Palavras-chave: caminhabilidade, participação popular, mobilidade urbana, centros urbanos.

\begin{abstract}
Pedestrians face mobility difficulties in urban centers due to heavy motor traffic and the lack of planning or planning that prioritize the car. In the last decades, studies on urban mobility have become more important in order to ensure the development of cities with plans to improve pedestrian mobility. As a way of evaluating this higher quality, we apply indexes of

\footnotetext{
${ }^{1}$ CARVALHO, Bady Nunes de; BARBOSA, Gisele S. A importância da participação popular no estudo da caminhabilidade. In: II SIMPÓSIO NACIONAL DE GESTÃO E ENGENHARIA URBANA: SINGEURB, 2019, São Paulo. Anais... Porto Alegre: ANTAC, 2019.
} 
walkability, which include a series of indicators on their conditions. The result of the measurement of these indicators consists in the basis of solutions. In this context, its effectiveness requires the attendance of an essential variable: the participation of pedestrians in the process of construction of alternatives. Based on this prerogative, this article aims to identify the elements inherent to the concept of walkability that has direct relation with popular participation. In order to do so, the work adopted as a methodology the bibliographical review on studies on popular participation in the planning of urban centers, concept of walkability and models of calculation of indicators of walkability. Based on this theoretical reference, the revised models are analyzed and the study then highlights the importance of popular participation, being the basis for future applications in cities and for studies of mobility and accessibility.

Keywords: walkability, popular participation, urban mobility, urban centers.

\section{INTRODUÇÃO}

Com o crescimento do tráfego motorizado, muitos espaços destinados aos pedestres foram perdidos. A redução das calçadas e a falta de hierarquia das vias, entre outros, configuram, muitas vezes, ambientes inapropriados para transeuntes nos centros urbanos (GEHL, 2013).

Diante disso, emerge a preocupação com a caminhabilidade, que consiste no conjunto de características que motivam as pessoas a caminharem pelos espaços públicos. A caminhabilidade é mensurada por diferentes atributos, como segurança e conforto, que influenciam diretamente na relação do usuário com o lugar que frequenta.

Estudos voltados para o cálculo do denominado "índice de caminhabilidade" se utilizam de diferentes formas de coleta de dados (e.g., a partir de pesquisas in loco, em sites públicos e análise de imagens de satélite). Nesse contexto, a inclusão dos pedestres no processo de construção de alternativas tem se mostrado relevante para a efetividade dessas soluções (BORDENAVE, 1989, 2007; SILVA e PELICIONI, 2013).

Com base nessa prerrogativa, o presente artigo tem como objetivos identificar e avaliar índices de caminhabilidade mediante a inclusão da participação popular no planejamento dos centros urbanos. A metodologia classifica-se como uma revisão bibliográfica com relação aos procedimentos técnicos e como qualitativa à forma de abordagem. Com base no referencial teórico, os modelos revisados são analisados e discutidos.

\section{PARTICIPAÇÃO POPULAR NO PLANEJAMENTO DOS CENTROS URBANOS}

A participação popular é essencial para a tomada de decisão dentro das cidades. Alega-se que pode ser alcançada em diferentes níveis: desde a elaboração de uma ideia até a avaliação final de um produto. O nivelamento em questão se relaciona com a participação ativa e/ou passiva dentro desses processos, onde entende-se que os papéis de gestão são associados a atividade, enquanto a passividade se associa ao papel de obediência das hierarquias sociais (BORDENAVE, 1989, 2007; SILVA e PELICIONI, 2013).

Essas interações no processo de tomada de decisão não garantem a contemplação de todas as partes envolvidas, gerando a marginalização de alguns grupos. Esta, por sua vez, consiste no processo de exclusão de uma pessoa ou um grupo da participação. Assim, há o surgimento do marginal, que não tem seus anseios contemplados.

Um exemplo enfrentado pelas grandes cidades do Brasil é a falta de equidade no planejamento dos transportes. Guimarães e Souza (2017) realizaram um estudo sobre o tema a partir da aplicação de questionários com profissionais da área. O estudo tem, como parte da conclusão, o reconhecimento de que as desvantagens sociais coexistem com as desvantagens relacionadas ao transporte. Desse modo, é reforçada a marginalização da população mais pobre, que não tem condições básicas para transporte atendidas.

Dentro desse contexto, há ainda os estudos sobre caminhabilidade, com foco na mobilidade urbana e que procuram garantir melhores condições de caminhada para os pedestres. Desse 
modo, pergunta-se: é possível que a garantia na mobilidade possa ser obtida sem participação da população?

\section{CAMINHABILIDADE E INDICADORES}

\subsection{Conceito}

A caminhabilidade consiste no conjunto de características que motivam as pessoas a ocuparem os espaços públicos. Seu estudo é essencial para que uma região se mantenha viva e saudável, diante da piora das condições para pedestres. De acordo com Gehl (2013), uma cidade viva é um lugar em que há certa massa crítica que queira utilizar os espaços públicos, devido a características que as atraiam. Além disso, o autor destaca a importância do espaço de transição, que consiste na relação entre os espaços públicos e privados (e.g. fachadas ativas que permitam a interação do pedestre com o interior).

Os elementos da paisagem urbana assumem funções distintas no estudo de caminhabilidade, pois interagem com os pedestres e têm influência nos fluxos realizados nas cidades. Destacase a importância desses elementos na paisagem urbana para a dinâmica da movimentação de pedestres por meio de incentivos, como fachadas ativas, bancos, praças. (CULLEN, 1974; ESCHHOLZ et al., 2018)

Um dos fatores destacados é o "ponto focal", que consiste em um referencial para a localização das pessoas no espaço (LYNCH, 1980). Para sua identificação, é importante que se conheça a população que frequenta a região de estudo, de modo a compreender os aspectos locais e culturais que funcionam para os cidadãos como referência, podendo ser um elemento qualquer que se diferencie no espaço. A avaliação desse fator é importante para a compreensão do espaço, visto que influencia nas dinâmicas dentro de sua área de influência.

A ocupação das ruas é essencial para as boas condições de segurança nas cidades. Nesse sentido, Jacobs (2003) destaca a existência de "olhos da rua", que consistem nas atividades das cidades que interagem com o espaço público. Tais atividades atuam como "vigias naturais", possibilitando reações a qualquer anormalidade que aconteça no espaço.

Como base de sua argumentação, a autora (JACOBS, 2003) ilustra seu ponto de vista através de depoimentos de moradores que relatam suas relações com os bairros onde residem. Tal participação é apresentada como parte do processo de compreensão das dinâmicas do espaço, visto que a segurança não obtém respostas somente pelo traçado e por dados específicos, mas também pelo tipo de resposta que o entrevistado compartilha.

Bentley et al. (1999) apresentam sete características que o desenho urbano deve contemplar: permeabilidade, variedade, legibilidade, versatilidade, imagem apropriada, riqueza perceptiva e personalização. O estudo se utiliza de recursos visuais e métodos de cálculos para a adequação do desenho a tais qualidades, além de passo-a-passo de como destacar cada uma dessas características. Dentre as implementações, há, para o cálculo de variedade, a necessidade de estudo da demanda social, que deve anteceder o estudo econômico para o estabelecimento de quais atividades precisam de mais espaço. Para isso, os autores (BENTLEY et al., 1999) recomendam que os desenhistas busquem por autoridades locais (e.g. associações de moradores) para conhecer quais são essas demandas e como podem incluí-las nos projetos.

A partir das considerações dos autores, o estudo de caminhabilidade apresenta uma série de fatores a serem considerados. Para facilitar a realização das intervenções desejadas, diversos índices de caminhabilidade que lidam com as urgências de cada categoria foram desenvolvidos. 


\section{2 Índices de caminhabilidade}

Um índice de caminhabilidade consiste em uma ferramenta para medir as condições do ambiente urbano que são determinantes para a circulação de pedestre, e tem como conclusão a apresentação de recomendações a partir dos resultados obtidos (ITDP, 2018).

Para Bradshaw (1993), a caminhabilidade é calculada por meio de 10 critérios com 4 opções de múltipla escolha, com avaliação final feita a partir da soma dos valores. Alguns critérios definidos pelo autor incluem: densidade de pessoas nas calçadas, probabilidade de encontrar alguém conhecido enquanto caminha e a idade que uma criança é permitida de andar sozinha. A coleta de dados proposta por Bradshaw pode ser realizada a partir de levantamentos e aplicação de entrevistas em campo, além da coleta por imagens de satélite e agências públicas.

Outro método para mensuração da caminhabilidade é o desenvolvido pelo Instituto de Políticas de Transporte e Desenvolvimento (ITDP Brasil), em 2016. A versão mais atual da ferramenta, desenvolvida em 2018, apresenta 15 indicadores que são divididos em 6 categorias: calçada, mobilidade, atração, segurança pública, segurança viária e ambiente, configurando-se, assim, em um conjunto de elementos mais complexos de mensuração em relação ao desenvolvido por Bradshaw (1993). A coleta de dados proposta pelo ITDP é realizada por métodos primários e secundários, se utilizando tanto de levantamentos de campo como de fotografias aéreas, recursos georreferenciados e documentos de administração pública.

Além disso, há outras formas de se estudar a caminhabilidade como Pelissari e Degreas (2017) que utilizam uma metodologia composta por medição de fluxos e permanências, aplicação de entrevistas e exposição de um painel interativo. A medição de fluxos e permanências é realizada a partir da contagem de pedestres em pontos específicos da região de estudo, determinados de acordo com indicações da literatura. Essa medição permite a identificação dos pontos de maior concentração e a sua relação com elementos das ruas. Um dos resultados, obtidos a partir de entrevistas, é a geração de uma nuvem de palavras útil para a compreensão dos fatores que incomodam os frequentadores da região. Além, o método inclui a criação de um painel utilizado para registrar como as pessoas avaliam a mobilidade urbana para os pedestres nas áreas analisadas.

\section{ANÁLISE E DISCUSSÃO}

Com a apresentação dos métodos de medição e dos pensamentos dos principais autores de caminhabilidade, é possível desenvolver uma relação entre os conteúdos. Levando em consideração os aspectos de participação popular e o pensamento dos principais autores sobre o tema. Pôde ser feita, então, a composição do quadro a seguir, que classifica os trabalhos quanto a presença ou ausência desses aspectos. 
Quadro 1 - Comparação dos métodos revisados de cálculo de índices de caminhabilidade

\begin{tabular}{|l|l|l|l|}
\hline Aspectos presentes nas medições & $\begin{array}{l}\text { Bradshaw } \\
\text { (1993) }\end{array}$ & ITDP(2016) & $\begin{array}{l}\text { Pelissari e } \\
\text { Degreas (2017) }\end{array}$ \\
\hline Entrevistas nas ruas (obrigatoriamente) & Sim & Não & Sim \\
\hline Estudo de fluxo de pedestres & Não & Sim & Sim \\
\hline $\begin{array}{l}\text { Entendimento popular dos fluxos de } \\
\text { pedestres }\end{array}$ & Não & Não & Sim \\
\hline Estudos de pontos focais & Sim & Não & Não \\
\hline Uso do solo & Não & Sim & Não \\
\hline Estudo de Demanda Social & Não & Não & Não \\
\hline Segurança & Sim & Sim & Não \\
\hline Segurança pela visão do pedestre & Sim & Não & Não \\
\hline
\end{tabular}

Fonte: Bradshaw (1993); ITDP (2016); Pelissari e Degreas (2017). Adaptado pelos autores, 2019.

Conforme apresentado no Quadro 1, o estudo de Bradshaw (1993) é o único que se atenta à presença de pontos focais e da segurança pela visão do cidadão. O estudo de Pelissari e Degreas (2017) é o único que investiga, por meio de consulta popular, as condições de fluxo na região de estudo. O índice do ITDP (2016), por sua vez, é o único que estuda a divisão de uso do solo. Esse último índice, por mais que seja o mais completo dos três em relação ao fluxo de pessoas e características do traçado urbano, é o que menos faz questionamentos aos pedestres e à comunidade local.

Com isso, percebe-se que os estudos buscam diferentes maneiras de compreender as características da caminhabilidade. Entretanto, é importante retratar que a busca para obtenção desses dados encontra incompatibilidades com o que alguns dos principais autores sobre o tema destacam. O ponto focal, apresentado por Cullen (1974), a segurança pelo ponto de vista do cidadão, destacado por Jacobs (2003), e a busca pelas demandas sociais, conforme Bentley et al. (1999), não são todos avaliados em cada um dos casos, podendo ocasionar em diagnósticos incoerentes com as demandas do espaço. Ainda, sem a participação popular no processo, a validação do índice pode se tornar ainda menos precisa.

\section{CONCLUSÃO}

A construção de alternativas para a melhoria das condições de caminhada é essencial para - combate das perdas de espaço para o tráfego motorizado nas grandes cidades. Nesse contexto, a adoção da participação popular pelos estudos de caminhabilidade assume papel importante de compreensão das necessidades da região para que a implementação seja eficiente.

Desse modo, é necessário que os atributos dos índices de caminhabilidade se atentem a uma coleta de dados cada vez mais completa, sendo capazes de contemplar as características do traçado urbano, mas também de entender as peculiaridades e as demandas locais da população, levando em consideração pontos levantados pelos principais autores sobre o tema. Dessa forma, os pedestres passarão a assumir uma participação mais ativa para a construção de alternativas e o diagnóstico dos índices de caminhabilidade serão mais precisos e coerentes com as demandas locais.

\section{REFERÊNCIAS}

BENTLEY, I. et al. Entornos Vitales - Hacia un diseño urbano y arquitectónico más humano manual prático. Editorial Gustavo Gili, SA, Barcelona. 1999. 
BORDENAVE, J. O que é participação. São Paulo: Brasiliense s.a.1989.

BORDENAVE, J. O que é participação. 8a Edição. São Paulo: Brasiliense s.a. 2007.

BRADSHAW, C. Creating - And Using - A Rating System For Neighborhood Walkability Towards An Agenda For "Local Heroes". 1993. Disponível em:

<https://www.cooperativeindividualism.org/bradshaw-chris_creating-and-using-a-ratingsystem-for-neighborhood-walkability-1993.htm>. Acesso em: 20 de abril de 2019.

CULLEN, G. El paisaje urbano: tratado de estética urbanística. Editorial Gustavo Gili, AS, Barcelona. 1974.

ESCHHOLZ, B. et al. Identificação e classificação de elementos da paisagem urbana em espaços públicos da cidade. II Simpósio Brasileiro Online de Gestão Urbana. 2018.

GEHL, J. Cidades para pessoas. São Paulo: Perspectiva. 2013.

GUIMARÃES, T., LUCAS, K. O papel da equidade no planejamento de transportes no Brasil. Institute for Transport Studies University of Leeds. 2017.

ITDP. Índice de caminhabilidade - Aplicação Piloto. Rio de Janeiro: Institute for Transportation and Development Policy - Brasil. 2016.

ITDP. Índice de caminhabilidade Versão 2.0 - Ferramentas. 2018. Disponível em: < http://itdpbrasil.org.br/icam2/ > Acesso em: 20 de abril 2019.

JACOBS, J. Morte e Vida de Grandes Cidades. São Paulo: Martins Fontes. 2003.

LYNCH, Kevin. A imagem da Cidade. São Paulo: Martins Fontes. 1980.

PELISSARI, M., DEGREAS H. Cidades para pessoas: caminhabilidade, forma urbana e diagnóstico da R. 25 de Março. InSitu, São Paulo, 3 (Especial): 117-127. 2017.

SILVA, E., PELICIONI, M. Participação social e promoção da saúde: estudo de caso na região de Paranapiacaba e Parque Andreense. Ciência \& Saúde Coletiva, 18(2):563-572. 2013. 